But it is not any answer to project our responsibility and our guilt upon the arms manufacturers of the USA, or of any other state, or to deny our self-seeking beneath the wing of governments which seem to see antidote to military threat through escalation of armament. The reality is that all of us who are comfortably off are sharing in the profitability of those industries.

Two things are necessary. Our national, and therefore our fiscal, policies must be orientated more towards the wellbeing of poor nations with less emphasis on our own economic security. That means that our desire for freedom must be a genuine and total aspiration and not merely as a defence against Soviet hegemony. And we must come to the point where one side will be prepared to take the risk of being at least marginally the less well armed of the two. But how to get there?

Could we say to the Communists that we deplore much of their policy, that we see their distaste for our more liberal regimes but that we are prepared to talk and in some measure to trust. Dare we not count on some trace of genuineness in their response? Provided that we can put our own house in order.

David T. MAClay

65 Fiery Hill Road

Birmingham

\section{Training in psychiatry for developing countries} Dear Sirs

I spent one year (1982-83) doing private practice in general psychiatry in Mauritius, an island in the Indian Ocean. It was with great interest, therefore, that I read Dr J. L. Cox's report of the 4th Conference of the African Psychiatry Association (Bulletin, April 1984, 8, 69-70). In 1979, when the DPM (Conjoint Board) was being discontinued, APIT (Association of Psychiatrists in Training) published a letter regarding the demise of the examination and the need for a substitute. In a sense, the new diploma from the Institute will fill a void created by the cessation of the DPM.

Perhaps the College should now develop a MRCPsych (Ext), tailored to the needs of overseas countries (especially Africa). Otherwise we will end up with two postgraduate diplomas: one prestigious, the other, perhaps, less so, even though it may be more relevant to the needs of the recipient countries.

Academic Department of Psychological Medicine Ely Hospital, Cardiff

\section{DeAR Sirs \\ 'Clomipramine Challenge Test' \\ Dr Holmshaw (Bulletin, April 1984, 8, 76) refers to a} clomipramine diagnostic test. I prescribe clomipramine, initial dosage of $75 \mathrm{mg}$ daily, to obsessive compulsives with affective symptoms. My findings are as follows:

1. Patients with primarily obsessive compulsive disorder respond satisfactorily, but perhaps may need increase of initial dosage to $225 \mathrm{mg}$ daily.

2. Patients with basic neurotic personalities become hyperexcitable, complaining especially of insomnia, even at a low dosage of $75 \mathrm{mg}$ daily.

3. Patients with bipolar affective disorder develop hypomanic symptoms following increase of the administered dosage.

4. Patients with primarily schizophrenic illness become acutely paranoid, which proves to be reversible on stopping clomipramine.

It would be interesting to know of the findings of other colleagues.

Ormskirk and District General, Hospital,

G. K. GAD

\title{
Review
}

Video Violence and Children: Part II. Children's Viewing Patterns and Parental Attitudes in England and Wales. A Report of a Parliamentary Group Video Enquiry. Published by Oasis Projects. 1984. f5.

Video recorders are recent additions to the paraphernalia of home entertainment and, as shown in this report, have rapidly become commonplace, climbing high on the list of many families'priorities. In response, the video shops and video clubs have sprouted fast, first in the big cities and are now to be found in every neighbourhood. Abuse almost invariably follows highly popular enterprises. Concern about commercial abuse, pirating of copyright by illegal copying, preceded concern about the abuse of children exposed to the sadistic and pornographic material invading a large number of homes.

Earlier this year, a Private Member's Bill was presented to the House of Commons. The introduction of this Bill provided the impetus for the inquiry, sponsored by a Parliamentary group. The names of those on the Working party and of those actively engaged in the investigation are listed in the report. It is acknowledged that there was a tight time schedule so that the data could be available for the Committee stage of the Bill.

The results as presented are disturbing. Forty-five per cent 
of children between the ages of 7 and 16 are said to have watched at least one of the 34 video films considered to be so violent or so obscene as to merit the attention of the Director of Public Prosecutions. Twenty-two per cent of children are reported as having seen 4 or more of the videos on the DPP's list, now grown to 51. Habitual watchers are said to come most frequently from inner cities and suburbs and from the North of England, but less often from rural areas and from Wales or East Anglia.

The investigation included questions about other films and television programmes. In twenty per cent of the sample of 4,500 children, the questionnaires given to children could be seen alongside the answers their parents had given to questions on their opinions. It is clear that parents have little idea of the range of unsavoury stimuli to which their children are exposed. The effect of parental attitude is much less clear. The research workers were interested in the ages at which parents allowed their children to watch Benny Hill or Carry On films. Since one of my pleasures in the past has been to feed small boys on knickerbocker glories and then watch them rolling in the aisles at a Carry On film, I looked eagerly for possible correlations. However, the parental statements can be, and indeed are, interpreted in different ways to support opposing arguments. A total ban on Grange Hill may be one way to head for trouble.

Certainly many children seem to enjoy horror films and they relish the freedom of running them over and over again, with particular emphasis on the 'best' bits. When David Warner loses his head rather neatly in The Omen, the moment is quickly passed in the cinema, but on video the full horror can be repeated, slowed up, frozen or even popped on and off.

Violence is some films, as in The Deerhunter, can make a serious and even highly moral point. To complete this review, I sampled one of the videos mentioned in this report. It was totally lacking in artistic merit and the story existed only as an excuse for revelling in violence, blood and cannibalism, with a more subtle undercurrent of particular brutality towards the old and the handicapped. I was nauseated but I am very concerned at the thought of the large number of children, and indeed adults, who are seemingly unaffected by such a video and the others like it.

This research report is concerned with a very important subject. It, however, is not published by a reputable scientific journal and so has not been subjected to critical peer review. It is, as they confess, a hurried piece of work. The details given of the methodology, particularly of the sampling technique, are inadequate and. the bland assurances of the reliability of the questionnaires are not convincing. This is a pity. Research of this sort can well have the opposite effect to what the well meaning sponsors intended.

ANn Gath

Drummond Clinic

Bury St Edmunds, Suffolk

\section{News Items}

\section{MIND Wallchart on the Mental Health Act 1983}

MIND has produced an authoritative wallchart on compulsory detention under the Mental Health Act 1983. It presents information on Sections 2, 3, 4, 5, 135, 136, 37 and 41 and covers six aspects of management: duration of detention; procedure; medical recommendation; removal to hospital; discharge; and Mental Health Review Tribunals.

The wallchart, measuring $23^{\prime \prime} \times 16 \frac{1}{2}$, is colour-coded for easy reference. It costs $£ 1.20$ (including postage and packing) and is only available from: MIND Bookshop, 155 Woodhouse Lane, Leeds LS2 3EF.

\section{Code of Practice for Discharging Patients}

The National Schizophrenia Fellowship has recently produced a booklet entitled 'Good Relations: A Code of Practice for those Discharging Patients'. The NSF feel that a recognized code of procedure should be followed when discharging patients who may not be fully capable of maintaining themselves independently in the community. It emphasizes the need to identify a 'caring' or 'concerned' relative or friend to whom the patient would wish to go on discharge in the belief that such a person has a key part to play in the caring for the patient in the community and could, with benefit to all concerned, fit into the healing and management processes.

Copies of the booklet are available at a cost of 30p (45p including postage) from the National Schizophrenia Fellowship, 78-79 Victoria Road, Surbiton, Surrey KT6 4NS. (Discounts are available for bulk orders.)

\section{Peter Beckett Postgraduate Research Award}

The Peter Beckett Postgraduate Research Award, worth approximately $£ 300$, will be given to the candidate who, in the opinion of the Award Committee, has carried out the best research project in psychiatry during his or her postgraduate training. This research should normally have been carried out in Ireland. The Award is open to all postgraduate trainees in psychiatry who have completed at least three years of a formal training programme approved by the Committee. Applications should reach the Medical School Office not later than 31 December 1984 and should include a description of the completed research project. Address: Medical School Office, Faculty of Medical and Dental Sciences, Trinity College, Dublin 2. 